\title{
The Features of the Manifestation of Primary School Students' Creativity in the Context of Graphic Activities
}

\author{
Irina Zelenkova \\ Moscow State Regional Institute of Humanities and Social Studies \\ Moscow, Russia
}

\begin{abstract}
The article deals with some of the features of the manifestation of primary school students' creativity in the context of graphic activities. The article analyzes the possible reasons for the low level of creative manifestations of pupils in the school environment. We present the results of the recearch in which we examine the interconnection of creative components and the dominant and problematic areas that are highlighted in the structure of younger pupils' creativity. The author outlines the perspective lines of development of primary school students' creativity in graphic activities.
\end{abstract}

Keywords-creativity; creative motivation; emotional experience; creative thinking; aesthetic qualities and abilities; primary school age; graphic activities

\section{INTRODUCTION}

Creativity is a complex phenomenon, determined by a wide range of factors, including both intellectual and nonintellectual (personal, social) ones. Many researchers think that the creative process is a specific process in different fields of human activity and knowledge [1], [2], [3]. Formulating a psychological model of creativity, we single out the following structural components which better reflect the features of artistic activities: motivational, emotional, intellectual, and aesthetic.

A motivational component of creativity explains the bent for activity as well as the intensity and persistence in the realization of the chosen action and in the achievement of the results. The singularity of creative motivation is determined by a wide range of interests [4]. The main features of these interests are constancy and variability.

Sensitivity is one of the main systems that provide creative forms of human activity. Creative activities are emotionally charged actions when complex cognitive processes are formed to develop emotional experience [5]. Emotions do not only coincide with the creative process, but also determine its quality and results.

Real creative progress requires high intelligence in most spheres of human activity, although a higher level of intelligence leads to creative expressions [6]. The success of creative activities is primarily determined by special qualities of the mental processes. Intellectual components of creativity, being general for any its field, are quite enough represented in artistic activities.

Aesthetic components of creativity are completely represented in the sphere of artistic activities and fine arts. They provide an aesthetic side of the creative process and its result, allowing a person to discover and improve the world, himself and his life according to the laws of beauty and harmony.

All the structural components of creativity that we considered determine the creative nature of the activity and provide immediate availability of artistic activity for an individual. During the process certain components of creativity are linked together forming complex patterns. However, the process is nonlinear and age-specific.

\section{RESEARCH METHODOLOGY}

The object of our research was to investigate the features of young students' creativity in fine arts.

We sorted out diagnostic techniques and worked out the criteria for evaluating each of the separate components of creativity. The diagnostic program included mono-profile methods to diagnose individual creative parameters, and multi-profile methods for complex diagnostics [7].

In the course of our research, we took into account that creativity is in fact notable for spontaneity of manifestation, and the results of the test procedures may not coincide with the real creative human achievements under natural conditions: the abilities are revealed, especially when there is freedom in the choice of activity, in forms of its implementation, in a possibility of creative work [8].

Graphic activity is aimed at creating a new form and breaking the rules. It provides an environment conducive to the natural appearance of the creative process, so we built up our study on a combination of standardized methods identifying common, mainly cognitive indicators of creativity and projective art-techniques that allow us to identify those creative characteristics that are best represented in the field of artistic activity.

We also took into account that creativity can manifest itself both in the process of an on-site graphic activity of an individual, and in the process of his perception of the works 
of art, however, in each case different components of creativity are accented. Therefore, for the diagnosis, we selected techniques that involve interaction with the fine arts at two levels: perception of art work and creating an on-site artistic image by means of fine arts.

\section{DESCRIPTION OF RESULTS}

The study involved 120 primary school pupils (children of 7-10 years) in Kolomna, Moscow. We found the prevalence of low levels of creativity children have in this age group (76.6\%). $22.5 \%$ of students can be attributed to the middle level of creativity. Students with a high level of creativity, make up only $0.9 \%$. Such low results are an indication that in the early school years the process of becoming a student as the subject of graphic activities has not been completed yet, besides being usually done spontaneously. The lack of purposeful pedagogical supervision and misunderstanding of the specifics of artistic and creative activities have a negative impact on the development of younger students' creativity. [9], [10].

We also recorded the attitude of many teachers to the behavioral characteristics of creative students as to deviant behavior that is consistent with the findings of other researchers [11]. Such an approach demonstrates a misunderstanding of the nature of creativity and rejecting the individual characteristics of the child.

Thus, the creative characteristics of primary school age students under the negative influence of the educational environment do not receive further development and, at the end of this sensitive period, reduce at all. This general trend is manifested as an increase of low and mid-level decline of creativity by the end of primary school.

Studying the structure of creativity of primary school pupils showed that among primary school children the dominant group mainly shows emotional components of creativity (mean - 2.76 points). This is consistent with the data of developmental psychology about the features of emotional development of children in this age group.

Despite the fact that according to numerous data, a significant portion of the manifestations of creativity relates to the characteristics of thinking, the group of intelligent components of creativity takes only the second place among primary school children (mean -2.42 points). This is due to the fact that the intellectual correlates of creativity require special work to develop, which is not always carried out. In addition, the orientation of the system of education affects the development of those aspects of intelligence that are connected with the left hemisphere of the brain, while the researchers emphasize the special role of the right hemisphere of the brain forcreative activities (V.S. Rotenberg, S.M. Bondarenko, R .M. Granovskaya et al.), as well as the dominance of the right hemisphere among primary school children [12].

The level of development of creative motivation among primary school children is also low (mean - 1.85 points). It is widely considered that from the end of the pre-school age to the end of the primary school age the graphic activities' significance is accepted as a stable, self-motivated initiative. However, our findings do not completely agree with this thesis. In recent years, scientific and technological progress has substantially changed the environment in which the formation and development of the child's personality take place. For example, according to the results of a students' survey, many of them did not include painting and art work in their sphere of interest. Modern children devote much time to watching TV programs and are addicted to computer games and gadgets. This information allows us to take a fresh look at the problem of organizing graphic activities for children: we should pay more attention to the development of the motivational component due to greater integration of innovative technologies in the system of art education of students.

The group of aesthetic components of creativity forms a problematic area in the structure of creativity of primary school students (mean - 1.56 points). This age group is characterized by sensitivity to artistic influences [13]. However, the aesthetic development of the students within the school is fragmented and unmethodical, and an independent transfer of aesthetic qualities and abilities to the field of their creativity has not been formed yet.

In general, it can be noted that the age-related changes of creativity during the primary school age are manifested in reducing the figures on all components, except the motivational one.

We also carried out the analysis of the structure of young students' creativity (based on the correlation analysis), which allowed us to identify the main lines of the development of creativity in graphic activities in primary school age.

Firstly, it is the motivational-emotional component that reflects the age characteristics of emotional development of children, as well as the role of emotions in the implementation of activities (a low level of voluntary behavior). We may note moderate closeness of the relationship $(0.41-0.5)$ between motivation and emotions manifested in graphic activities of primary school pupils. In addition, the group of emotional components is the dominant one in the structure of young students' creativity, although their importance is gradually declining: among children of 7-8 years emotions have a direct impact on the motivational components of their activity and on manifestations of intellectual activities, and among children of 9-10 years this effect is mediated and the connection of emotions with other components is not so clear.

Secondly, it is the interconnection between the intellectual and aesthetic components of creativity (also reasonable closeness of connection). Specificity of graphic activities of younger students becomes apparent in the pursuit of reliable transmission of the characteristics of the imagined object. Some kind of "intellectualism" in the expression of the essence of the subject, a special semantic expressiveness, is increasingly manifested in paintings. The development of signs and symbolic thinking allows students to perceive and evaluate the aesthetic components of reality 
in a more appropriate way. [14]. Pupils reinforce positive motivation for aesthetic activities, which creates conditions for further development of the aesthetic components of creativity.

\section{CONCLUSIONS}

The study of peculiarities of small children's creativity in artistic activities made it clear that they are characterized by the predominance of a low level of creativity, the irregular development of its components, ambiguous and sometimes weak connection between them, indicating the complexity and nonlinearity of the process of creativity formation in artistic activities as systematic mental education.

The dominant features in the structure of creativity of small children are emotional components determined the actual direction of the psychological phenomenon, but their influence is decreased and becomes indirect by the fourth class.

The potential line of the development of primary school children's creativity in artistic activities forms a unit of motivation, characterized by positive dynamics during all the primary school age. The strong connection of intellectual and aesthetic creative components, caused by the dominant right-brain of small children and their sensitivity to artistic influences, also creates the prerequisites for the further development of the components of creativity in artistic activities and their transition on new level.

\section{REFERENCES}

[1] M. Csikszentmihalyi. (1988) Society, culture, person: A systems view of creativity. In R..J. Sternberg (Ed.) The Nature of Creativity. Cambridge: Cambridge University Press, pp. 325-339.

[2] D. Feldman, M. Csikszentmihaly and H. Gardner (1994) Changing the world: A framework for the study of creativity. Westport, CT: Praeger

[3] R. Sternberg, T. Lubart (1995) Defying the crowd: Cultivating creativity in a culture of conformity. N. Y.: Free Press.

[4] C. Martindale. (1989) Personality, Situation, and Creativity. In Glover, J.A., Ronning, R.R. and Reynolds, C.R. (eds.), Handbook of Creativity. Plenum Press, New York, pp.211-232.

[5] T.A.Amabile, S.G. Barsade, J.S Mueller,. and B.M Staw,. (2005) Affect and Creativity at Work. Administrative Science Quarterly, 50: 367-403.

[6] E. P. Torrance (1988). The nature of creativity as manifest in its testing. In F. J. Sternberg (Ed.), The nature of creativity. Cambridge: Cambridge University Press, pp. 43-75

[7] I.V. Zelenkova. The development of creativity of primary school students in art-graphic activity in different learning environments. Dis. ... Cand. psychol. Sciences: 19.00.07. - St. Petersburg, 2006. $173 \mathrm{p}$

[8] M. A. Wollach, N.A. Kogan, (1965) A new look at the creativity intelligence distinction. Journal of Personality, 33: 348-369.

[9] I.V. Zelenkova Opportunities of Creative Pedagogy in realization of primary school students' creative potential under conditions of graphic activity // The development of creative potential of the individual and society: materials of the international scientificpractical conference. - Prague: Vědecko vydavatelské centrum "Sociosféra-CZ", 2013. - p. $92-99$
[10] I.V. Zelenkova The problem of future teachers training to develop the children's creativity through art and graphic activity. // The world of childhood and education: materials of IV All-Russian scientificpractical conference with the representation of the CIS countries. Magnitogorsk Magnitogorsk State University, 2010. - P. 190-198

[11] V.S. Yurkevich Modern problems of working with gifted children // Psychological Science and Education (e-zine). 2010. - № 5. Date of reference http://psyedu.ru/journal/2010/5/Yurkevich.phtml 25.03.2015

[12] V.M. Polyakov, L.I. Kolesnikova Functional asymmetry of the brain in ontogenesis (review of the literature of native and foreign authors) // Bulletin of ESSC SB RAMS, 2005, №5 (43). - P. 206-215

[13] T.A. Barysheva Creativity. Diagnosis and Development: Monograph. - SPb .: Publishing House Herzen Herzen, 2002. - 205 p.

[14] E.V. Zvonova Understanding of art work in the development of spiritual and human creativity. Collections Conference SIC sociosphere. 2014. № 2. - P. 088-095 